\title{
APONTAMENTOS SOBRE A GUARDA COMPARTILHADA
}

\author{
Bianca Stephanie Cita, Olivie Samuel Paião \\ Universidade do Oeste Paulista - UNOESTE, curso de Direito, Presidente Prudente, SP, E-mail: \\ olivie-samuel@hotmail.com
}

\section{RESUMO}

O presente artigo visa a conceituar e a elucidar o instituto da guarda compartilhada e os pontos positivos que esta apresenta em relação aos filhos menores, quando da dissolução da sociedade conjugal. A metodologia constou de pesquisas bibliográficas, resultante da leitura e análise de leis, resoluções e artigos eletrônicos. Os dados obtidos foram analisados, utilizando-se o método hipotético-dedutivo. Os resultados são satisfatórios nos casos em que a separação dos genitores acontece de forma consensual, beneficiando o menor, que terá o afeto e a participação de ambos os genitores em todos os âmbitos de sua vida. Conclui-se que este tipo de guarda se apresenta como método menos desgastante para a criança, não afetando, profundamente, seu desenvolvimento pessoal e escolar, que é o principal resguardo no divórcio. Por fim, visa-se a divulgar esta modalidade de guarda, pois, ainda que se tenha regulamentação sobre o tema, demonstra-se pouco divulgado no âmbito universitário e familiar.

Palavras-chave: Guarda Compartilhada, Divórcio, Menor, Família, Filhos.

\section{NOTES ON SHARED GUARD}

\section{ABSTRACT}

The present article aims to conceptualize and elucidate the institute of shared custody and the positive points that it presents in relation to the minor children when the conjugal society is dissolved. The methodology consisted of bibliographical research, resulting from the reading and analysis of laws, resolutions and electronic articles. The data obtained were analyzed using the hypothetical deductive method. The results are satisfactory in cases where the separation of the parents happens in a consensual way, benefiting the less that will have the affection and participation of both parents in all areas of their life. We conclude that this type of custody presents itself as a less stressful method to the child, and does not profoundly affect their personal and school development, which is the main safeguard in divorce. Finally, it is intended to disclose this modality of custody, since even if there is regulation on the subject it shows little dissemination on the university and family.

Keywords: Shared Guard, Divorce, Minor, Family, Children.

\section{INTRODUÇÃO}

Atualmente, muito se fala em dissolução das entidades familiares. Assim, com o aumento significativo dos divórcios e a dissolução de uniões estáveis, reflexamente se aumentam as discussões acerca da guarda física (e sua modalidade), quando há menores frutos desses relacionamentos rompidos. Ademais, trava-se uma discussão jurídica em torno da proteção e tutela dos menores, no tocante à modalidade de guarda optada pelos pais e/ou pelo juízo. Por isto, faz-se necessário o entendimento do instituto da guarda no âmbito familiar, bem como suas modalidades e conceitos. 
Define-se a guarda como um direito inerente aos genitores de conviverem com seus filhos, a fim de exercerem o poder familiar imposto por lei, após a dissolução da união.

É de extrema importância ressaltar-se que não se confundem a guarda compartilhada com a guarda física e nem com a guarda alternada, posto que a guarda física é que detém a custódia do menor; ou seja, onde e com qual dos genitores o menor residirá. A alternada é uma subdivisão da guarda física, em que a guarda é alternada entre os genitores, ficando certo tempo com um genitor e certo tempo com outro. Diferentemente, a guarda compartilhada, em síntese, restringe-se à esfera jurídica, quanto às decisões a serem tomadas, em conjunto, pelos genitores/detentores da guarda, no âmbito social, escolar e individual concernentes ao menor.

A guarda compartilhada, alterada pela lei no 11.698/2008, apresenta novos detalhes importantes em torno da responsabilidade dos genitores sobre a criança e/ou adolescente. Nela, ambos os responsáveis têm uma postura ativa na tomada de decisões referentes ao(s) filho(s) e ao seu desenvolvimento.

A ausência desta modalidade de guarda pode ser prejudicial aos menores, haja vista a existência da Síndrome de Alienação Parental (SAP), que, em síntese, é influenciar a criança a criar um conceito negativo sobre o genitor que não possui a sua custódia, desmoralizando-o. Cabe essa ressalva, pois muito comum um dos progenitores praticarem a SAP como forma de atingir um ao outro, usando o filho para tal finalidade- prática totalmente nociva para a criança.

Portanto, objetiva-se afirmar que a guarda compartilhada se demonstra de suma importância, pois, além de evitar sofrimento psicológico para a criança e desgaste para os genitores, evita a chamada Síndrome de Alienação Parental (SAP). Apresenta-se, por fim, ser viável, pois, à medida que traz benefícios, tanto aos maiores (responsáveis; genitores) quanto aos menores, sejam púberes ou impúberes, diminuem as intervenções judiciais nas relações conjugais dissolvidas, para resolver os impasses entre genitores e o sofrimento dos menores.

\section{METODOLOGIA}

Os dados deste artigo foram obtidos por meio da aplicação do método hipotéticodedutivo. Tal método tem a finalidade de apontar uma viável e possível solução para um problema existente, ao enfrentá-lo, partindo de uma análise do geral para o particular.

Ademais, utiliza-se da pesquisa bibliográfica, resultante da leitura e análise de leis, resoluções e artigos eletrônicos e publicados que se fizeram produtivos para a elaboração deste trabalho.

\section{DISCUSSÃO}

Como já disposto no introito, a guarda, de modo geral, é disposta como quem detém a custódia da prole ou menor. Nos dizeres de Madaleno (2017, p. 420), assim pode ser definida a guarda:

A guarda é atributo do poder familiar, e se refere à convivência propriamente dita, constituído do direito de viver com o filho menor ou incapaz na mesma habitação, com o correlato dever de assumir a responsabilidade direta de velar pelos interesses do filho, a quem representa em juízo nas ações onde for parte, sendo a custódia uma decorrência da separação dos pais, tenham sido ou não casados. (sic)

Cumpre dizer-se, antes, nas conceituações dos tipos de guarda, que o que se leva em consideração, para a fixação da guarda, não é a conveniência dos pais, mas, sim, o interesse dos menores. Neste sentido discorre Rodrigues (2002, p.272): "Em todos os litígios em que se disputa 
a guarda de filhos, o julgador deve ter, em vista, sempre e primordialmente, o interesse dos menores". Em complemento, Viana também dispôs:

O quadro erigido pela doutrina e pela jurisprudência e a evolução operada na legislação pertinente traçam, com linhas fortes, o caminho que leva à proteção do bem do menor. Na vida prática, na solução de pendências que envolvem a guarda, não se cogita daquilo que atende às conveniências e interesses dos pais, mas se o menor encontra resposta para seus interesses. (1993, p. 42).

Assim, visando-se a tutelar os interesses dos menores, as diversas formas de guardas foram surgindo com o passar dos anos e estudos sociais. Dessa forma, atualmente, tem-se a guarda unilateral, guarda compartilhada, guarda alternada e, por fim, a pouco conhecida guarda nidal.

Na guarda unilateral, segundo os artigos 1.583, §1ํㅡ, e 1.584, além da guarda física, será dado apenas a um dos pais o encargo de criação do menor. A fixação desta modalidade de guarda pode-se dar em comum acordo entre os genitores ou por fixação pelo magistrado, que visualizará quem possui ou detém condições, para oportunizar a melhor educação e que possua bom relacionamento com o menor (IBDFAM, 2016).

Art. 1.583. A guarda será unilateral ou compartilhada. (Redação dada pela Lei no 11.698, de 2008).

$\S 1^{\text {ㅇ }}$ Compreende-se, por guarda unilateral, a atribuída a um só dos genitores ou a alguém que o substitua (art. 1.584, $\S 5^{\circ}$ ) [...]. (Incluído pela Lei no 11.698, de 2008).

[...]

Art. 1.584. A guarda, unilateral ou compartilhada, poderá ser: (Redação dada pela Lei no 11.698, de 2008):

I - requerida, por consenso, pelo pai e pela mãe, ou por qualquer deles, em ação autônoma de separação, de divórcio, de dissolução de união estável ou em medida cautelar (Incluído pela Lei no 11.698, de 2008);

II - decretada pelo juiz, em atenção a necessidades específicas do filho ou em razão da distribuição de tempo necessário ao convívio deste com o pai e com a mãe (Incluído pela Lei no 11.698, de 2008). (BRASIL, 2002).

Desse modo, a guarda unilateral trata de exclusividade de um dos genitores, quando há um consenso entre ambos ou quando um dos genitores não deseja a guarda compartilhada. Desse modo, a tutela é atribuída apenas a um dos genitores ou a outrem que o substitua. (DIAS, 2016)

O instituto da guarda alternada diz respeito à custódia do menor. A guarda física do menor fica sob os cuidados de um dos genitores por um determinado período, compreendido por semanas, meses ou, até mesmo, anos. Assim, o Instituto Brasileiro de Direito de Família conceitua a guarda alternada $(2016$, p. 340):

Alternada seria o mesmo que guarda dividida, ou seja, ora com um, ora com outro dos pais. [...] tem o sentido de uma guarda dividida, a tempo certo, permanecendo o filho na companhia e sob cuidados exclusivos de cada um dos pais nos períodos que lhes sejam cometidos- dia sim, dia não, semanas trocadas, períodos maiores ou menores, que podem variar 
segundo as conveniências dos pais, mas que nem sempre acordem aos superiores interesses dos filhos.

Em complemento, Guilherme Strenger diz: "Cada um dos cônjuges terá, alternativamente, segundo um ritmo definido por eles e adotado pelo juiz, a guarda da criação e, por essa via, os diferentes atributos aí vinculados, como educação, administração legal e posse legal" (2006 p. 65/66).

Entretanto, ainda que cada genitor tenha tempo determinado e exclusivo para o menor, assegura-se-lhe o direito de visita, afinal, dependendo do período que se estabelece, a guarda será uma privação de convivência do menor com um dos genitores, se este não puder ver o filho e as situações a que está submetido. Nesta toada, Casabona (2003, p. 258) reflete que, "enquanto um dos genitores exerce a guarda no período que lhe será reservado, ao outro se transfere o direito de visita. Ao final do período, a criança faz o caminho de volta, do guardião ao visitador, para, no tempo seguinte, se inverterem, novamente, os períodos".

Ocorre que a guarda alternada não se mostra saudável ao menor, não sendo aconselhada pela doutrina majoritária, jurisprudência e por profissionais da saúde. Segundo Manole (2009, p. 91), "esse modelo de guarda não se tem mostrado aconselhável, uma vez que a duplicidade de residências pode provocar instabilidade emocional e psíquica no menor".

Apenas a título de conhecimento, tem-se a guarda nidal. Tal modalidade é uma criação doutrinária, não tendo previsão em lei brasileira. É incomum e de difícil acontecimento, pois demanda consenso dos pais, sendo modelo aplicado mais nos Estados Unidos. Euclides de Oliveira conceitua, brilhantemente, este tipo de guarda:

Trata-se de um arranjo especial de custódia conjunta para casais separados ou divorciados que decidam manter o filho em uma única casa, enquanto eles, pais e outros parentes com direito a convivência, permanecem por períodos distintos nesse lugar, em companhia do filho. Trocam de turno, como se diz na linguagem laboral, permitindo à criança permanecer na mesma casa, enquanto recebe, ali, um dos pais, mas não os dois ao mesmo tempo. Ou seja, a mãe sai, quando chega o pai; e o pai vai embora, quando a mãe retorna, sem que o filho precise deixar o seu "ninho" de criação. (IBDFAM, 2016)

Por fim, e mais importante, a guarda compartilhada. Também denominada conjunta, difere-se da guarda alternada e consiste na corresponsabilidade parental. Nesta, ambos os pais têm convivência com o menor e tomam decisões, em conjunto, sobre as esferas que envolvem os interesses da prole. Diz respeito apenas à guarda jurídica, que se dividirá entre os genitores. $A$ custódia do menor, ou seja, a guarda física, ficará sobre a responsabilidade de um dos genitores. Assim, Canezin enfatiza que (2005, p. 12) "a guarda compartilhada, pai e mãe, divide a responsabilidade legal sobre os filhos, ao mesmo tempo, e compartilha as obrigações pelas decisões importantes relativas ao filho menor, quando aqueles estão separados".

Desse modo, em síntese, cabe fazer-se uma diferenciação entre guarda compartilhada e guarda alternada. Enquanto esta última se refere à alternância da guarda física do menor, ficando tempos com um genitor e tempos com outro, a guarda compartilhada estabelece que a guarda física do menor seja com apenas um dos pais, entretanto a guarda jurídica e a tomada de decisões serão feitas por ambos os genitores. 
O instituto da guarda compartilhada foi adotado como regra, a partir da lei no 13.058 , de 2014, que alterou os artigos 1583 e 1584 do código civil, sendo preservado, com prioridade, pelos tribunais. Veja-se (BRASIL, 2014):

[...] 1. A guarda compartilhada busca a plena proteção do melhor interesse dos filhos, pois reflete, com muito mais acuidade, a realidade da organização social atual, que caminha para o fim das rígidas divisões de papéis sociais definidas pelo gênero dos pais. 2. A guarda compartilhada é o ideal a ser buscado no exercício do Poder Familiar, entre pais separados, mesmo que demandem, deles, reestruturações, concessões e adequações diversas, para que seus filhos possam usufruir, durante sua formação, do ideal psicológico de duplo referencial. 3. Apesar de a separação ou o divórcio usualmente coincidirem com o ápice do distanciamento do antigo casal e com a maior evidenciação das diferenças existentes, o melhor interesse do menor, ainda assim, dita a aplicação da guarda compartilhada como regra, mesmo na hipótese de ausência de consenso. 4. A inviabilidade da guarda compartilhada, por ausência de consenso, faria prevalecer o exercício de uma potestade inexistente por um dos pais. E dizse inexistente, porque contrária ao escopo do Poder Familiar, que existe para a proteção da prole. 5. [...]. 6. A guarda compartilhada deve ser tida como regra, e a custódia física conjunta - sempre que possível - como sua efetiva expressão. (grifos pessoais)

Anterior à edição da lei 13.058/2014, tinha-se que, na guarda conjunta, os pais exerceriam, assim como exerciam no matrimônio, a guarda conjunta como forma de autoridade parental. Logo, no Brasil, a guarda conjunta ou compartilhada era tida como a prática do poder familiar, posto que, na época, somente haveria o exercício dessa guarda, se os pais mantivessem a harmonia conjugal ou estável convivência (MADALENO, 2017). Ademais, confundia-se, muito, a guarda compartilhada com a alternância da custódia da prole, ou seja, com o instituto da guarda alternada- que já foi objeto de diferenciação acima.

De outra banda, a fixação da guarda compartilhada corrobora para que não se tenha a existência da Síndrome de Alienação Parental, que, para Jorge Trindade (2007, p. 282), "se trata de programar uma criança, para que ela odeie, sem justificativa, um de seus genitores, cuidando a própria criança de contribuir na trajetória de desmoralização do genitor visitante". Nesta toada, Pedrosa e Bouza (2009) complementam ser prática habitual o pai ou a mãe inferir no relacionamento dos menores para com o outro ascendente, provocando um sentimento de rejeição e exclusão do outro progenitor e seus familiares. Gera-se, assim, um "sentimento nato de defesa contra a fictícia ameaça que representa seu pai ou sua mãe" (PEDROSA; BOUZA, 2009, p. 9).

Cabe dizer-se que há impossibilidades de aplicação da guarda compartilhada em algumas situações. Quando os pais tomam a atitude de desmembrar a sociedade conjugal mas têm um relacionamento regado de conflitos e ausência de harmonia, tendo, em verdade, uma disputa de ego entre um e outro, há verdadeira chance de ocorrer alienação parental, sendo incabível a guarda compartilhada; briga entre os genitores frente ao menor, dentre outros desprestígios que afetariam, diretamente, a modalidade de guarda e, de suma importância, o menor. Ademais, incabível será a adoção dessa prática conjunta de guarda, quando há processo penal em face de um dos genitores que tenha atentado contra a vida, liberdade física ou sexual, integridade moral de um dos filhos ou do outro progenitor (ESPANHA apud MADELENO, 2017). 
Logo, haverá quem pergunte se, para que a guarda compartilhada seja implantada, há de ter consenso entre os pais. Antes da edição da lei da guarda compartilhada, aplicava-se apenas aos divórcios consensuais, excluindo-se os litigiosos, pois necessário seria um absoluto consenso entre os genitores. Dessa forma, conforme dispõe Madaleno (2017, p. 438), "não há lugar para a guarda conjunta entre casais ditos amargos, conflituosos e que encontram, no filho, o troféu de todas as suas dissensões judiciais e extrajudiciais". Atualmente, aplica-se aos divórcios litigiosos, desde que os pais entrem em um consenso quanto à criação dos filhos menores, e não mantenham verdadeira "guerrilha" entre si. A real intenção da guarda compartilhada é tutelar os direitos e interesses dos menores, pouco importando o sentimento de um genitor para com o outro, mas, sim, como isto se manifestará e refletirá na prole, afetando sua saúde e eventualmente provocando problemas emocionais e psicológicos. Logo, não necessita de total consensualismo entre os genitores, mas que exista uma flexibilização na qual se permita exercer o desenvolvimento pacífico e educativo quanto ao menor, visando, unicamente, ao bem-estar deste (RODA Y RODA, 2014).

\section{CONCLUSÃO}

Denota-se, portanto, que, de todos os tipos de guarda explicitados, o que se mostra mais viável é a guarda compartilhada. Esta modalidade apresenta os melhores caminhos ao bom convívio familiar entre os genitores e os menores, proporcionando-lhes melhor estabilidade emocional e psicológica, não dando grande espaço ao sentimento de perda e vazio para o menor, quanto à dissolução da sociedade conjugal. Ademais, os conflitos menos intensos, entre os pais, não podem afetar o desempenho do poder familiar inerente a cada um dos pais, pois se trata de encargo legal, não podendo nenhum dos dois eximir-se de tal responsabilidade.

Isto posto, ainda que existam divergências quanto à modalidade de guarda a ser aplicada, deve prevalecer a Guarda Compartilhada, levando, sempre, em consideração os interesses dos menores envolvidos, evitando o sofrimento e influenciando um bom desenvolvimento das proles, devendo os pais, a comunidade, o Estado e todo o meio social, influenciar e induzir a adoção desta guarda, e conscientizar, uns e outros, de que, quando do divórcio/separação, que envolva menores, os interesses pessoais dos genitores deverão ser deixados de lado, para não prejudicar o exercício da guarda e atrapalhar a evolução dos filhos.

\section{REFERÊNCIAS}

AKEL, Ana Carolina Silveira. Guarda compartilhada: um avanço para a família. 2a ed. São Paulo: Atlas, 2009.

BRASIL. Código Civil. Lei no 10.406, de 10 de janeiro de 2002. Disponível em: http://www.planalto.gov.br/ccivil_03/leis/2002/L10406.htm. Acesso em: 24 jul. 2017.

BRASIL. Superior Tribunal de Justiça. Recurso Especial 1428596 RS 2013/0376172-9. Recorrente: JCG. Recorrido: CG. Relatora: Ministra Nancy Andrighi. Publicado no DJe 25/06/2014. Disponível em: https://stj.jusbrasil.com.br/jurisprudencia/25178209/recurso-especial-resp-1428596-rs-20130376172-9-sti/inteiro-teor-25178210. Acesso em: 03 ago. 2017.

CANEZIN, Claudete Carvalho. Da guarda compartilhada em oposição à guarda unilateral. Revista Brasileira de Direito de Família, São Paulo, Ano VI, n. 28, Fev-Mar. 2005.

CARCERERI, Pedro Augusto Lemos. Aspectos destacados da guarda de filhos no Brasil. Disponível em: http://www.jusnavegandi.com.br/doutrina/texto.asp. Acesso em: 02 ago. 2017. 
CASABONA, Marcial Barreto. $O$ instituto da guarda e sua modalidade compartilhada. Dissertação - Pontifícia Universidade Católica de São Paulo, São Paulo, 2006.

DIAS, Maria Berenice. Manual de Direito da Famílias. 11a ed. atual. e ampl. - São Paulo: Editora Revista do Tribunais, 2016.

LEVY, Fernanda Rocha Lourenço. Guarda de filhos: os conflitos no exercício do poder familiar. São Paulo: Atlas, 2008.

LUZ, Valdemar p. da. Manual de Direito de Família. Manole, 2009. Disponível em: https://integrada.minhabiblioteca.com.br/books/9788520446591/pageid/0. Acesso em: 04 jul. 2017.

MADALENO, Rolf. Direito de família. 7ạ ed. ver., atual. e ampl. - Rio de Janeiro: Forense, 2017.

OLIVEIRA, Adriana Maria Evaristo Martinez de. et al. Normas e padrões para trabalhos acadêmicos e científicos da unoeste. 3 ed. Presidente Prudente: Universidade do Oeste Paulista, 2015. Disponível em: <http://www.unoeste.br/site/biblioteca/documentos/ManualNormalizacao.pdf?v=6>. Acesso em: 23 jul. 2017.

PEREIRA, Rodrigo da Cunha (Org.). Tratado de Direito das Famílias. 2 ed. Belo Horizonte: IBDFAM, 2016.

RODA Y RODA, Dionisio. El interés del menor en el ejercicio de la pátria potestad. El derecho del menor ser oído. Navarra: Tomoson Reuters Arazandi, 2014.

RODRIGUES, Silvio. Direito Civil: vol. 6, São Paulo: Saraiva, 2002.

STRENGER, Guilherme Gonçalves. Guarda de Filhos. 2a ed. São Paulo: DJP Editora, 2006.

TRINDADE, Jorge. Manual de psicologia jurídica para operadores do Direito. 2. ed. Porto Alegre: Livraria do Advogado, 2007. 